\title{
Agricultura familiar campesina y cadenas cortas agroalimentarias: la Feria Municipal de Yuty - Caazapá (Paraguay)
}

\author{
Agricultura familiar camponesa e cadeias curtas agroalimentares: a Feira \\ Municipal de Yuty - Caazapá (Paraguai)
Peasant family farming and short agri-food chains: the Municipal Fair of Yuty- Caazapá (Paraguay)

\author{
Francisca Danaides Carreras Rios ${ }^{1}$ \\ Valdemar João Wesz Junior ${ }^{1}$
}

Recibido el 09/12/2019; revisado y aprobado el 26/02/2020; aceptado el 21/03/2020. DOI: http://dx.doi.org/10.20435/inter.v21i4.2815

\begin{abstract}
Resumen: Las cadenas cortas se consolidaron como uno de los principales mercados para la agricultura familiar campesina, con destaque a las ferias de productores. El objetivo de este estudio es describir y analizar las características generales de la Feria Municipal de Yuty y comprender la importancia de ese espacio para los agricultores y consumidores. Esta investigación empezó con una revisión bibliográfica, análisis de datos secundarios y una investigación previa a cuatro personas que en ese momento estaban ligadas a la feria. Luego, en la siguiente visita a la feria, se aplicó una encuesta a nueve productores (la totalidad de feriantes que estaban en el día) y once consumidores presentes en la feria. Los resultados encontrados indican que la Feria Municipal Yuty tiene una gran importancia entre los productores que comercializan en este espacio, sobretodo porque venden a un precio satisfactorio todos los productos que llevan. Además, la feria es muy relevante para el ingreso de las familias de productores y para el fomento del mercado local. Ya los consumidores van a la feria porque encuentran productos frescos, exclusivos y con precio atractivo, al mismo tiempo que tienen una buena relación con el feriante. En este sentido, la feria de Yuty es una forma de acceso al mercado que beneficia a productores y consumidores, generando procesos más inclusivos de desarrollo y contribuyendo con la seguridad alimentaria y nutricional.
\end{abstract}

Palabras clave: agricultura familiar campesina; cadenas cortas agroalimentarias; Feria Municipal de Yuty.

Resumo: As cadeias curtas se consolidaram como um dos principais mercados para a agricultura familiar camponesa, com destaque às férias de produtores. O objetivo deste estudo é descrever e analisar as características gerais da Feira Municipal de Yuty e entender a importância desse espaço para agricultores e consumidores. Esta pesquisa começou com uma revisão da literatura, análise de dados secundários e uma investigação prévia de forma exploratória a quatro pessoas que, nesse momento, faziam parte da feira. Posteriormente, na seguinte visita à feira, foi aplicado um questionário a nove produtores (todos os comerciantes que estavam no dia) e a onze consumidores presentes na feira. Os resultados encontrados indicam que a Feira Municipal de Yuty tem grande importância entre os produtores que comercializam nesse espaço, sobretudo porque vendem a um preço satisfatório todos os produtos que levam. Além disso, a feira é muito importante para a renda das famílias produtoras e para o fomento do mercado local. Os consumidores vão à feira porque encontram produtos frescos, exclusivos e com preços atrativos, ao mesmo tempo em que mantêm um bom relacionamento com o comerciante. Nesse sentido, a feira de Yuty é uma forma de acesso ao mercado que beneficia produtores e consumidores, gerando processos de desenvolvimento mais inclusivos e contribuindo para a segurança alimentar e nutricional.

Palavras-chave: agricultura familiar camponesa; cadeias curtas agroalimentares; Feira Municipal de Yuty.

Abstract: The short chains have consolidated themselves as one of the main markets for family peasant agriculture, with emphasis on the holidays of producers. The objective of this study is to describe and to analyze the general characteristics of the Municipal Fair of Yuty and understand the importance of this space for farmers and consumers. This research began with a literature review, secondary data analysis, and an exploratory investigation of four people who, at the time, were part of the fair. Subsequently, a survey was applied to nine producers (all of the people of fair that were on the day) and eleven consumers present at the fair. The results found indicate that the Municipal Fair of Yuty has a great importance among the producers that commercialize in this space, especially because they sell at a satisfactory price all the products they carry. In addition, the fair is very important for the income of producer families and for the promotion of

\footnotetext{
${ }^{1}$ Universidad Federal de la Integración Latinoamericana (Unila), Foz do Iguaçu, Paraná, Brasil.
} 
the local market. In this sense, the Yuty fair is a form of market access that benefits farmers and consumers, generating more inclusive processes of development and contributing to food and nutritional security.

Keywords: peasant family farming; short agri-food chains; Municipal Fair of Yuty.

\section{INTRODUCCIÓN}

En el Paraguay, la agricultura familiar campesina ${ }^{2}$ es numéricamente importante ( 9 de cada 10 fincas), sin embargo detienen solamente 6,3\% de la superficie total en 2008. Mismo con tan poca tierra, generaba en este año 32,0\% del valor bruto de la producción agrícola y detenía $28,4 \%$ de la población ocupada a nivel nacional (ZARZA, 2017). Además de estos valores, diferentes autores muestran la pertinencia de este grupo para la seguridad y soberanía alimentaria del país, en la preservación del modo de vida tradicional paraguayo, en la promoción de mejores condiciones sociales en el campo, en la preservación de la biodiversidad, en la promoción de un manejo agrícola más sustentable, en la generación de más ocupaciones en espacio rural etc. (TORRES FIGUEREDO, 2008; RIQUELME, 2016; ANGULO, 2017; GONZÁLEZ, 2017).

Pero, los dos últimos Censos Agropecuarios traen un dato preocupante sobre la agricultura familiar campesina de Paraguay: entre 1991 y 2008 las fincas con menos de 50 ha tienen una reducción de 7,8\% en el número de unidades y de 15,8\% en su superficie, en cuanto que las fincas con mayores áreas crecieron $23,4 \%$ y $35,5 \%$ en estas dos variables, respectivamente (MAG, 2009). Esto sigue una dirección contraria a lo establecido en la Constitución Nacional en los artículos referidos a la Reforma Agraria y el Desarrollo Rural, en los cuales se hablan de la incorporación de la población campesina al desarrollo económico del país y la eliminación del latifundio (RIQUELME, 2016).

Una de las principales dificultades de la agricultura familiar campesina en Paraguay es en la comercialización de sus productos, considerando que el sistema agroalimentario ha pasado por procesos de concentración empresarial, internacionalización de los mercados, padronización de los productos y construcción de nuevas normas de calidad (WILKINSON, 2008). Por un lado, este contexto dificulta la participación de los pequeños agricultores en los mercados convencionales, aun así, está ganando visibilidad las ferias agroalimentarias como una alternativa más adecuada para este segmento de productores (GOVERDE-LIPS; BRUIL; RENTING, 2015). Es importante decir que las ferias son uno de los principales ejemplos de cadenas cortas de abastecimiento, comprendidas como expressão da vontade dos atores envolvidos em uma cadeia de valor em "[...] construir novas formas de interação entre produção e consumo, mediante o resgate da procedência e da identidade dos produtos, assentada não apenas em critérios de preço, mas também em valores sociais, princípios e significados simbólicos, culturais, éticos e ambientais" (GAZOLLA; SCHNEIDER, 2017, p. 12).

Este trabajo tiene como foco la Feria Municipal de Yuty (Departamento de Caazapá Paraguay), que se ubica en pleno microcentro del municipio e ocurre dos veces por semana (martes y viernes). La feria, que es la única del distrito, fue impulsada en el año 2002 y cuenta con la participación de más o menos 10 familias productoras que ahí comercializan sus productos. La elección de esta feria ocurre porque solo participan agricultores familiares campesinos, hay

\footnotetext{
2 En Paraguay, la definición considera "aquella actividad productiva rural que se ejecuta utilizando principalmente la fuerza de trabajo familiar para la producción de un predio; que además no contrata en el año un número mayor de 20 jornaleros asalariados de manera temporal en épocas específicas del proceso productivo, que residen en la finca y/o en comunidades cercanas y que no utiliza, bajo condición alguna sea en propiedad, arrendamiento, u otra relación, más de 50 hectáreas en la Región Oriental y 500 hectáreas en la Región Occidental de tierras independientemente del rubro productivo" (REAF, 2007, p. 4).
} 
una gran diversidad de productos y cuenta con la presencia de consumidores locales. Además, los autores ya tenían contactos previos con actores de este distrito.

El objetivo de este estudio es describir y analizar las características generales de la feria del municipio de Yuty y comprender la importancia de ella para los agricultores familiares campesinos y para los consumidores de la localidad. Para poder realizar el estudio, empezamos con una revisión bibliográfica y con un levantamiento de datos del MAG (Ministerio de Agricultura y Ganadería) y del DGEEC (Dirección General de Encuesta Estadístico Censal), con destaque al Censo Agropecuario del Paraguay y el Atlas Censal del Paraguay - Caazapá. En la secuencia se realizó una investigación exploratoria previa e informal con cuatro consumidores de la feria (mujeres) entre los días 25 y 26 de abril de 2016. En el día 3 de mayo (martes) de 2016 fue hecha la visita en la feria para poder realizar la encuesta a los productores y consumidores, que fue aplicada a 9 productores (la totalidad de feriantes que estaban ese día) y 11 consumidores presentes en la feria. Es importante destacar que las encuestas y la investigación previa fueron realizadas en la lengua guaraní para mejor recopilación de los datos.

Después de esta Introducción, este trabajo abordará el tema de las cadenas cortas agroalimentarias y evidenciará experiencias de ferias que están presentes en Paraguay. En la secuencia gana destaque algunos aspectos generales de Caazapá y de Yuty. El ítem posterior es sobre la Feria Municipal Yuty, que es el foco principal de este trabajo, y por último están las Consideraciones Finales.

\section{CADENAS CORTAS AGROALIMENTARIAS: ALGUNAS EXPERIENCIAS EN PARAGUAY}

En los últimos años nuevas prácticas agroalimentarias son implementadas como estrategia para mejorar las condiciones de vida de los productores rurales y de los consumidores, creando formas diferenciadas de relación campo/ciudad (WILKINSON, 2008). Una de estas prácticas es la comercialización vía ferias de productores en los espacios urbanos, que se en algunos lugares es una tradición histórica, en otros, como en Yuty, es una experiencia reciente, que fue implementada con la intención de reducir intermediarios entre el productor y el consumidor final. Además de las ventajas económicas (en general el productor gana más por su producto y el consumidor paga menos de que cuando se suman diferentes intermediarios en el medio de esta relación), los productos son más frescos y el consumidor puede conocer quien cultiva, los métodos utilizados en la producción, aprender nuevas formas de preparo etc. Como sintetiza Goverde-Lips, Bruil y Renting (2015, p. 40), estos espacios “[...] possibilitam relações mais diretas entre consumidores urbanos e produtores e apontam para novas perspectivas. Os consumidores obtêm alimentos frescos, sazonais e com preços acessíveis, geralmente produzidos de forma agroecológica, enquanto os produtores recebem remuneração mais justa".

Estas prácticas son reconocidas en la literatura como cadenas cortas o circuitos cortos, así como circuitos de proximidad, circuitos locales, circuitos alternativos, redes alimentarias alternativas etc. (ROSSI; BRUNORI; GUIDI, 2008; CEPAL, 2016). Dentro de estas denominaciones generalmente están incluidas la venta directa (productor al consumidor), que puede ser en las ferias, entrega del producto a domicilio o su compra en la casa del productor, así como la venta semi-directa, en donde solo hay un intermediario, que puede ocurrir, por ejemplo, dentro de una cooperativa o asociación (DAROLT; LAMINE; BRANDEMBURG, 2013). La mayor parte de estas iniciativas buscan justamente el encortamiento de las distancias (físicas, sociales, culturales, económicas) entre el mundo de la producción y del consumo (GAZOLLA; SCHNEIDER, 2017). 
En nivel mundial creció mucho el número de experiencias de circuitos cortos y de proximidad en la transacción de alimentos entre productores y consumidores. En Paraguay también existen experiencias de comercialización directa de productos agrícolas, siendo más presente los agricultores que, en el interior del país, salen de sus casas para comercializar su producción agropecuaria en las calles de las zonas urbanas. Y también hay las ferias, siendo una de las más conocidas el Cecoproa (Centro de Comercialización para Productores Asociados), que se encuentra en la capital del país (Asunción), que es administrada por el MAG a través de la Dirección de Comercialización. El Cecoproa fue creado en el año 1994 y es un espacio propio para la comercialización de los productos provenientes de la agricultura familiar dentro del Mercado Central de Abasto de Asunción (DAMA). Según datos del MAG (2018), 60 organizaciones (comités, asociaciones y cooperativas) usufructuaron del espacio, beneficiando a casi tres mil familias de agricultores de diferentes departamentos del país.

Otra feria de gran importancia en Paraguay ocurre en Ciudad del Este, que es el segundo municipio con mayor población del país, llamada Central de Productores Hortigranjeros Feriantes de Alto Paraná. Según Red Rural (2016), esta iniciativa existe a más de 20 años e involucra 1.507 productores de 18 distritos, organizados en 104 comités. "La feria, con un promedio de 380 a 400 productores que realizan venta directa a los consumidores de lo producido en sus fincas, genera un ingreso anual aproximado de USD 4.054.000." (RED RURAL, 2016, p. 59). A la feria concurren entre 10.000 y 12.000 clientes por semana provenientes de Ciudad del Este y sus alrededores, donde encuentran diversos productos, como

[...] carne de cerdo, oveja y cabra, leche, queso, huevos, pescado, gallinas, dulces caseros, verduras y frutas. Recientemente (año 2015), se incorporó un patio de comidas típicas en el cual se elaboran, a la vista del público, alimentos tradicionales producidos por las socias feriantes con productos agroecológicos procedentes de las fincas. (RED RURAL, 2016, p. 61).

Otro caso conocido en Paraguay es la Feria "De la Colonia a tu mesa", que nació en marzo del 2015 en la ciudad de Asunción con el apoyo de la Instituto Nacional de Desarrollo Rural y de la Tierra (INDERT) y con el respaldo de la Municipalidad de Asunción. Hoy en día es considerada una feria con mucho éxito, y los feriantes vienen de los departamentos de San Pedro, Caazapá, Misiones y Central. La feria, que se realiza una vez por mes, se promueve con la participación de los Comités de Mujeres, a través de la Dirección General de Género del INDERT. Se pueden encontrar diferentes productos en la feria: carnes de vaca, cerdo, oveja, cabras, gallina casera, cecina del Chaco y queso Paraguay, o degustar platos tradicionales como locro, cecina, sopa de pescado, chorizo Pa'i Puku, chipa asador, leche natural pasteurizada del Chaco, así como frutas y hortalizas, entre otros (INDERT, 2016).

Por fin cabe destacar la Feria "Jakaru Porã Haguã", que en español significa para "comer bien", que se realiza desde el año 2012 en Asunción con el apoyo del Slow Food y de otras entidades. Conforme Bogado Martínez (2016, p. 29), "[...] en ella participan 20 comunidades indígenas y campesinas, con productos caseros y ecológicos, junto a conocidos chefs que cocinan en vivo, ofreciendo platos tradicionales a precios accesibles". Según la autora, la feria recibe

[...] en la plaza uruguaya a cientos de consumidores ávidos de productos frescos llegadas de las chacras campesinas. En pocas horas ya casi todos los productos son comercializados, tanto como las verduras y frutas de estación. [...] El público puede degustar desde variedad de comida tradicional (chipa, mbeju, vori vori, sopa paraguaya, sopa so'o, etc), alimentos vegetarianos y veganos. (BOGADO MARTíNEZ, 2016, p. 29-30). 
Además de estas experiencias más reconocidas, en los pequeños distritos del país también es muy tradicional la presencia de ferias agroalimentarias, como en Yuty, que vamos a presentar más adelante.

\section{ASPECTOS GENERALES DE YUTY (CAAZAPÁ - PARAGUAY)}

El Departamento de Caazapá tiene una superficie de 9.496 km2 y 172.345 habitantes, siendo más de $80 \%$ población rural (DGEEC, 2016). Está limitado al norte con los departamentos de Guairá y Caaguazú, al sur con el departamento de Itapúa, al este con el departamento de Alto Paraná, al oeste con los departamentos de Misiones y Paraguarí. Caaguazú está dividido en 11 distritos: Abai, Buena Vista, Caazapá, Doctor Moisés S. Bertoni, Fulgencio Yegros, General Higinio Morínigo, Coronel Maciel, San Juan Nepomuceno, Tavaí, Yuty y 3 de Mayo (Figura 1). "La mayor parte de la población económicamente activa pertenece al sector primario (actividades agropecuarias), concentrándose en este sector el 60,0\% de la misma, mientras que el sector terciario (comercio y servicios) concentra al 31,0\% de esta población en el año 2012" (DGEEC, 2016, p. 58).

Caazapá tenía 22.899 fincas en 2008, distribuidas en un área de 768.220 hectáreas. Una de las características del Departamento (que nos es diferente del país) es la concentración de la tierra, pues las fincas consideradas como de agricultura familiar campesina (con hasta 50 hectáreas) son $96 \%$ de las unidades, pero solo detienen 19\% del área. Por otro lado, 0,5\% de los productores (aquellos con más de mil hectáreas) controlan $64 \%$ de la superficie mapeada por el Censo Agropecuario de 2008. Entre las principales actividades del Departamento está la mandioca (en 90\% de las fincas), aves (88\%), poroto (88\%), maíz (84\%), porcinos (76\%) y vacunos (60\%), además de que 79\% tienen huertas familiares. Otros cultivos (algodón, maní, soja, caña de azúcar, trigo, forestales, yerba mate) y creaciones (ovinos, caprinos, equinos) también están presentes, pero en menos de la mitad de las fincas (MAG, 2009).

Figura 1 - Localización del Departamento de Caazapá y de sus distritos

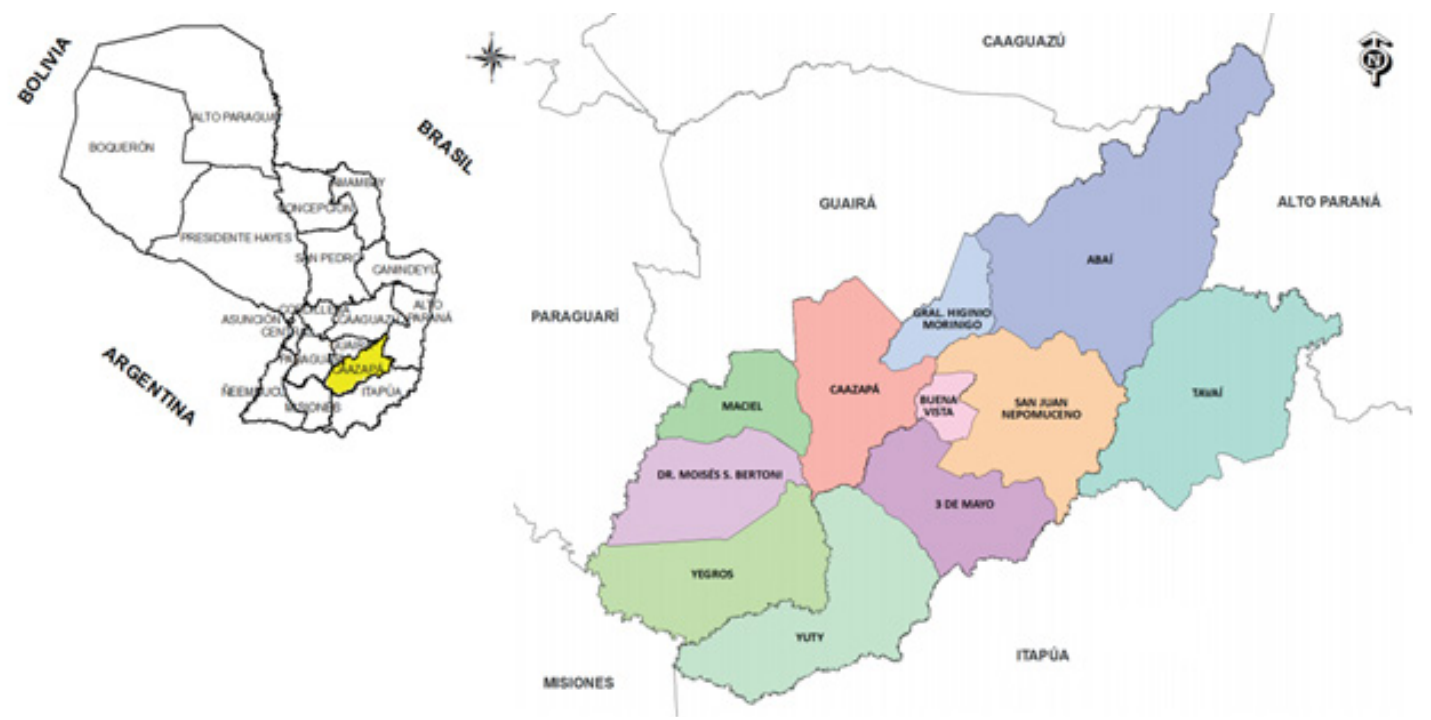

Fuente: DGEEC (2016).

Yuty es uno de los distritos más antiguas y tradicionales del Paraguay, pues fue fundada en 4 de octubre de 1611 por el sacerdote Franciscano español Fray Luis de Bolaños (TESSADA, 2002). Con más de 400 años desde su fundación, su territorio fue siendo reducido con los 
desmembramientos de otros distritos. Actualmente tiene una superficie de $1.440 \mathrm{~km}^{2}$ y su población es de aproximadamente 20 mil habitantes, sabiendo que el área urbana cuenta con más o menos 6 mil habitantes (DGEEC, 2016).

Según el Censo Agropecuario Nacional de 2008, el distrito de Yuty tenía 4.912 fincas y la superficie total de ellas era de 185.205 hectáreas (media de 37,7 hectáreas). La mayoría de esas fincas $(96,6 \%)$ esta manejada por un solo productor, pero también hay productores asociados y sociedades empresariales. El nivel de educación de los productores es bajo, la mayoría con un nivel de escolaridad que va hasta el sexto grado (85\%) y muy pocos son los que llegan hasta la universidad (2\%). Sin embargo, $6 \%$ de los encuestados (productores) se declararon analfabetos. El Censo también permite identificar otras características: $92 \%$ de los productores residen en la finca; $70 \%$ viven en la misma explotación a más de 10 años; 99,7\% son paraguayos; la media de miembros que viven en la finca es 3 personas; $50 \%$ de los productores trabajan solemnemente en la finca, $44 \%$ trabajan dentro y fuera, $2 \%$ fuera y 3\% no realizó ningún trabajo; $19 \%$ tienen acceso a asistencia técnica y $13 \%$ a financiamiento rural.

En términos de actividades productivas, el cultivo más popular era la mandioca ( $93 \%$ de las fincas producían en 2008), seguido por el poroto (89\%) y el maíz (72\%). Los cultivos menos presentes fueron arroz, trigo, sésamo, soja y la yerba mate, con menos de $2 \%$ de las unidades produciendo, mientras que la caña, maní y algodón estaban en situación intermediaria. Además de esto, el $85 \%$ indicaron que tenían huerta en la finca. La creación de pequeños animales (pollos y porcinos) también cuenta con alta incidencia (más de $80 \%$ ), así como es importante el ganado (66\%) y vacas lecheras (44\%). En suma, los agricultores de Yuty tienen pequeñas dimensiones territoriales y una producción agropecuaria diversificada, con algunos productores comercializándolos en la feria de la ciudad - como vamos presentar adelante.

\section{LA FERIA MUNICIPAL DE YUTY}

En este ítem focalizaremos en el tema central de este trabajo, o sea, las características generales de la Feria Municipal de Yuty, así como abordaremos quien son los productores que exponen sus productos, agregando también la importancia de este espacio de comercialización para ellos y las dificultades encontradas, además de la impresión de feria desde la perspectiva de algunos consumidores.

\subsection{Características generales de la feria}

La Feria Municipal de Yuty está ubicada al costado de la Terminal de Ómnibus, situada en el centro de la ciudad. La Feria fue impulsada en el año 2002 por ingenieros agrónomos que querían ayudar a las familias productoras a comercializar sus productos. Al inicio no tenían un lugar propio, y por esto alquilaban un espacio que quedaba a pocas cuadras de la plaza, sobre la calle Independencia Nacional. Después de 4 años aproximadamente, se ubicaron en la plaza y luego se mudaron al costado de la terminal de ómnibus de la ciudad, donde actualmente se encuentran. Este cambio ocurrió en la gestión del Intendente Municipal Dr. Edgar José Walko (periodo 2006- 2010), que inauguró un nuevo local para los feriantes el 17 de marzo de 2010, para 15 miembros de la feria, garantizando un local propio y bien estructurado (Figura 2).

Las familias que forman parte de la feria vienen de diferentes distritos que se encuentran alrededor de la ciudad (pueblo), como Mbocajaty, Itangu'a, San Juan, San Isidro, Tiri, Guasukai, 
Jaguarete Kora, Loma Yruguaiy y Jakura'a. A pesar de que los caminos vecinales no se encuentran en muy buen estado y considerando que son caminos que no están pavimentados, los agricultores siguen apostando a la venta de sus productos dentro de la ciudad. Las familias venden productos de origen vegetal y animal como: kumanda (poroto), avati moroti ha pyta (maíz blanco y rojo), mandi'o (mandioca), kure ñandy (grasa de chancho), avatiky (choclo), dulce de maní, avatiku'i (harina de maíz), aramiro (almidón casero), kamby (leche), kurero'o (carne de cerdo), manduvi (maní), jety (batata), perejil, orégano, cevoi rogué (cebolla de verdeo), tomate, locote, eirete (miel de abeja), eira (miel negra), ryguasu reongue (gallina cacera), ryguasu rupi'a (huevo casero), quesú (queso), miel, zapallo, andai (calabaza), arveja, naranja, mandarina, limón etc.; y, dependiendo de la época, sandia y melón. Todos los productos son traídos directamente de las propias chacras para la feria.

Figura 2 - Feria Municipal de Yuty

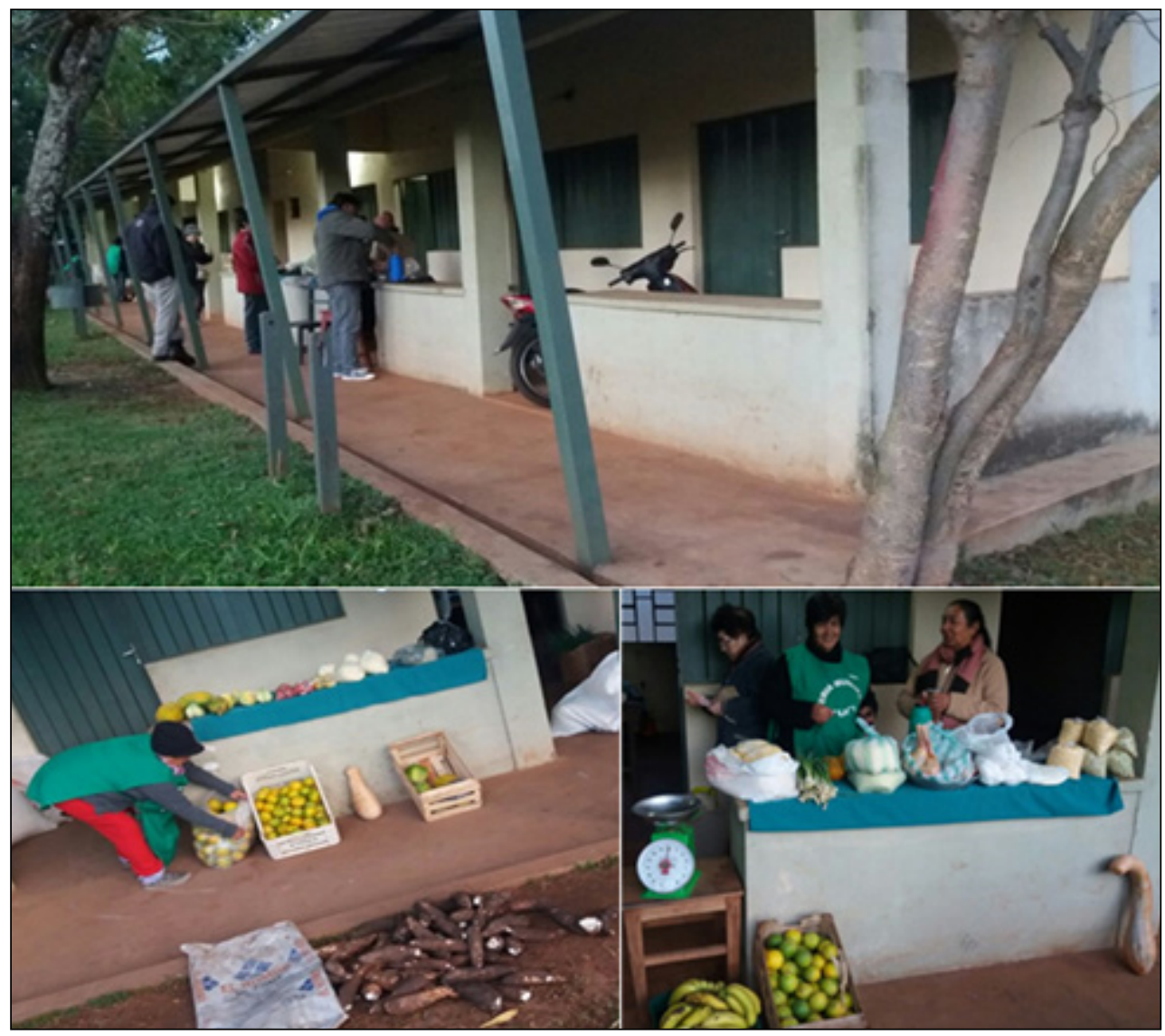

Fuente: Investigación de campo (2016).

En las primeras horas de la mañana (4h o 4:30h) de los días martes y viernes estas personas vienen hasta la ciudad de Yuty a vender sus productos. Cuando llegan, los feriantes ya van acomodando sus productos, cada un organizando para que los clientes puedan elegir lo que mejor les parezca. El horario máximo de atención es hasta 8:30 de la mañana aproximadamente, cuando prácticamente todos los productos ya fueron comercializados. Los productores trasladan sus productos en colectivo o motocarro y se organizan en grupos de tres o dos personas para pagar al chofer que maneja la motocicleta. Pero, en función de las malas condiciones de los caminos vecinales, la feria no se realiza en los días de lluvia. 
Un punto en consideración es que, en la mayoría de los casos, las personas hacen sus pedidos con anticipación y los feriantes lo entregan en el día. Es común, por ejemplo, las encomiendas de los restaurantes, que compran como mínimo $5 \mathrm{~kg}$ de harina de maíz o también el queso, que tiene mucha demanda y es utilizada en muchos platos. Así, además de la feria, hay productores que llevan sus productos directamente a los restaurantes, que sirve como opción complementaria de comercialización.

\subsection{Los productores de la feria}

Con la investigación de campo observamos que la mayoría de los feriantes son mujeres (8 mujeres y 1 varón), siendo que el hombre que estuvo en este día fue porque su esposa no pudo estar presente - en general es ella que viene a la ciudad para comercializar sus productos en la feria. Además de notar la participación de las mujeres dentro de la finca, también han tomado la responsabilidad de ir hasta la ciudad a comercializar los productos, como ya identificado en otros estudios (BURG, 2005; ZEEUW, 2010; ANACLETO; COELHO; CURVELO, 2016). Cuando preguntado porque ellas ocupan este espacio y no los hombres, las mujeres dicen que saben desenvolverse mejor dentro de la feria, como en la hora de manipular los productos, en la forma de organizar y en el modo de exhibición de los mismos. Argumentan que son más detallistas, saben los gustos y demandas de sus clientes, que en la mayor parte también son mujeres. Otro dato importante es que el $56 \%$ de los feriantes son mayores de 50 años y $89 \%$ tienen baja escolaridad (solamente el nivel primario).

La mayoría de estas personas viven en sus propias tierras, que varían desde 0,25 hasta 10 hectáreas. En este espacio tienen un cultivo diversificado de frutas, hortalizas y legumbres, que se altera dependiendo de la época del año. La producción es básicamente hecha con herramientas manuales, como azadas, machetes, ybuku (machete largo), arado con bueyes etc. Los productores también se dedican a criar algunos animales de tiro, como bueyes y caballo, y también hay cría de aves (gallinas y patos), vacas y cerdos, las cuales en épocas festivas (Semana Santa, Navidad y Año Nuevo) tienen ventas masivas en la feria, principalmente porque muchos visitantes vienen a reencontrar sus familiares en estos periodos. Además de la producción para la venta en la ciudad, las familias producen para su propio consumo, que ellos consideran como prioritario.

La mayoría de las familias está en la feria desde su comienzo. Y cuando se preguntó sobre las transformaciones ocurridas en la feria a lo largo de los años, dicen que no hay muchos cambios, excepto en la infraestructura, que ahora tienen el local propio, que facilita bastante a la hora de guardar sus cosas de forma segura en cada pieza.

Un elemento clave es la importancia de la feria cómo espacio de comercialización e ingreso económico para las familias, pues 7 de los 9 encuestados respondió que la venta es la única fuente de renta familiar, ya que no tienen otro trabajo y solo se sustentan con la comercialización de sus productos dentro de la Feria Municipal de Yuty. Los otros dos encuestados, justamente los con menores áreas de tierra, venden su fuerza de trabajo para ampliar la renta. Así, se puede decir que el sustento de estas familias depende fundamental de su propiedad rural (de donde proviene la producción para el consumo) y de la feria (que es su principal fuente de ingreso económico).

La mayoría de los productores están satisfecho con el precio de los productos (solamente uno se mostró insatisfecho) y el 56\% dijo que es posible solventar los gastos básicos de la casa con la venta de los productos, reforzando la importancia de la feria en el ingreso familiar. Y, cuando preguntamos sobre los principales beneficios de ser miembro de la feria, además de la mejora en la renta familiar, ellos destacaran que la venta es segura y rápida ("lo que se trae, se 
vende"). Otra respuesta fue en relación a la sociabilidad, tanto entre productores como entre productores y consumidores. Entre productores, destacan que se ayudan mucho entre ellos, sea compartiendo el transporte para llegar en la feria, sea vendiendo los productores del otro feriante cuando este no está en el momento. Entre productores y consumidores, ya hay una relación de confianza y de amistad, porque logran una relación directa y frecuente ("tenemos clientes fijos y, después de tantos años, ya son amigos”). Como comentaran Goverde-Lips, Bruil y Renting (2015), la feria es más que un espacio de comercialización, también es un espacio de encuentros, y esto influye de manera positiva en el ambiente laboral, generando una especie de ayuda mutua entre los productores y de unión con los consumidores.

Entre las dificultades encontradas, la respuesta más citada es el traslado de los productos, que se debe a la falta de movilidad propia y el tiempo que les lleva llegar hasta la ciudad, pues la mayoría proviene de las compañías aledañas y hay veces que los caminos estas intransitables (incluso se comentó la salida de miembros de la feria a causa de esto). Otra dificultad es la falta de apoyo por parte de las autoridades correspondientes, sea en términos de producción agropecuaria, pues 6 de los 9 productores dijeron que no recibe ninguna política pública para sus cultivos, sea por la falta de proyectos enfocados para la feria, que podría promocionar charlas técnicas, divulgación de los productos etc.

A pesar de estas dificultades, lo que se observa es la gran importancia de la feria para los agricultores, pues venden todos los productos que llevan y reciben un precio satisfactorio por sus productos (como afirmarán 8 de los 9 encuestados). En este sentido, la feria se consolida como un espacio que posibilita un ingreso seguro para las familias, valorizando el trabajo y el esfuerzo de estos campesinos. Aunque con las limitaciones que comentamos, este espacio de comercialización genera un abanico de oportunidades, sea para los propios productores como también para los consumidores, que presentaremos en el próximo ítem.

\subsection{Los consumidores de la feria}

La encuesta aplicada a los 11 consumidores fue realizada aleatoriamente en la ciudad de Yuty. Como características generales, 10 son del sexo femenino (pues son la gran mayoría de los frecuentadores de la feria), la media de edad es 53 años, la mayoría cuenta con una escolaridad básica incompleta y más de la mitad de los entrevistados son ama de casa (6) y el resto tiene otras funciones, como comerciante, limpiadora, albañil y costurera. La mayoría de las personas encuestadas compran los productos de forma semanal y quincenal en la feria. Cuando preguntado sobre los cambios identificados por los consumidores, en general destacan el local donde hoy en día se encuentran la feria y la cantidad de productores miembros, que van disminuyendo con respecto a años anteriores. Tanto para los productores como para los consumidores encuestados, esto ocurre a consecuencia de la falta de asistencia técnica para la manutención de los cultivos, de apoyo para el traslado de los productos y de asistencia crediticia, ya que para mantener un cultivo muchas veces es necesario comprar algunas herramientas, semillas y otros insumos agrícolas.

De acuerdo con las encuestas, la mayoría obtiene productos siempre del mismo productor, que se debe a las relaciones frecuentes, la calidez de la gente, por ser pariente, por conocer sus productos, por tener descuento etc. Sin lugar a dudas, la confianza es un punto a ser considerado ya que estamos hablando de un pequeño pueblo donde la mayoría de las personas se conocen, como ya retratado en otros estudios (CHENG; LACROIX, 2014; BORJA et al., 2017; GAZOLLA; SCHNEIDER, 2017, entre otros). A partir de las encuestas y del acompañamiento de las actividades 
de la feria, se pudo percibir que este espacio es más que un lugar de una simple compra y venta de productos. Esto porque, los feriantes se organizan de forma diferente y venden sus productos de manera distinta, donde los consumidores pueden conversar, tomar tereré y ejercer una relación más que simplemente comercial con productores rurales.

Los consumidores han hecho diferentes propuestas para mejorar la organización de la feria, como que se realice los fines de semana o más a menudo, que se incorpore más agricultores (lo que, consecuentemente, ampliará el volumen de productos) y que las autoridades locales apoyen de manera más sólida los feriantes, sobretodo en termino de mejora de los caminos vecinales o de disponibilidad de transporte (para que no haya ausencia de la feria en días de lluvia, por ejemplo). Uno de los encuestados comentó también que se haga propaganda en la radio para que las personas se enteren de las actividades hechas en la feria, como informar los días que vienen y que traen, sobre todo en los días festivos.

Un tema que llamó la atención fue que los consumidores no tienen noción del papel de la agricultura familiar campesina en la producción de alimentos, así como no reconocen la importancia de la feria dentro de la ciudad para fomento de la economía local. Tampoco ven la relevancia de los valores culturales y de las costumbres de los agricultores para la seguridad alimentaria. También se percibió que cuando los consumidores hablaban de la calidad, se referían a productos frescos y con buena apariencia, y no se vinculaba con la idea de productos sanos, orgánicos etc. - como muchas veces presenta la bibliografía. A partir de las encuestas con los 11 consumidores, se percibe que los principales elementos que tienen estimulado a la compra de los productos en la feria se vinculan con productos frescos, exclusivos (que no hay en otros establecimientos comerciales urbanos) y con buen precio, además de la buena relación con el feriante.

\section{CONSIDERACIONES FINALES}

A partir de este trabajo se puede destacar que la Feria Municipal Yuty tiene una gran importancia entre los productores que comercializan en este espacio, sobretodo porque venden todos los productos que llevan y la mayoría considera el precio satisfactorio. Otro tema clave es que este espacio es central para la renta familiar de los agricultores, incluso siete de los nueve encuestados comentaran que la venta en la feria es su única fuente de ingreso. Se por una parte esto evidencia la centralidad de este circuito comercial para la reproducción social de estos actores, por otro demuestra una alta dependencia que ellos tienen en este mercado, que es preocupante, por ejemplo, cuando llueve y no tienen como llegar en la ciudad, quedando sin ingreso en este período.

Aunque sean necesarias la implementación de diferentes políticas públicas para estos agricultores (como mejores condiciones para el traslado hasta el pueblo, asistencia técnicas y recursos para la producción y acceso a nuevos mercados, lo que demanda articulación de diferentes instancias y escalas gubernamentales), se tiene que reconocer que actualmente la feria cumple un papel clave en la economía de los agricultores feriantes. Además, ofrece a los consumidores productos frescos, diferenciados y con un precio justo, se confirmando como una opción alternativa a las cadenas de supermercados. Esto auxilia que los espacios rurales sean recuperados y vuelvan a producir alimentos para el consumo local, optimizando las pequeñas áreas de tierras que tienen los productores encuestados. Otro tema importante es que los miembros de la feria son mayormente mujeres, lo que promueve cambios significativos en términos de emancipación y empoderamiento de las agricultoras (pero no tuvimos condición de profundizar esta discusión es este trabajo).

Por fin, es importante destacar que promover la feria de agricultores genera oportunidades 
de promocionar la diversidad de productos agrícolas, recuperar costumbres y tradiciones, estimula el intercambio con otras familias y el respeto a los ciclos de cultivos, apuntando hacia la agrobiodiversidad dentro de las chacras. En este sentido, fortalece una forma de acceso al mercado que beneficia productores y consumidores, garantizando una opción de promoción para la seguridad alimentaria y nutricional de agricultores y de personas que viven en los pueblos y ciudades. Entre los productores que venden su producción en la feria, tratase de una alternativa central para minimizar la pobreza y generar procesos más inclusivos de desarrollo. Esto se torna aún más importante en distritos como Yuty, donde gran parte de la población rural es formada por agricultores familiares que tienen una producción agroalimentaria diversificada, pero poseen pocas oportunidades de acceso a mercados.

\section{REFERENCIAS}

ANACLETO, A.; COELHO, A. P.; CURVELO, E. B. C. As mulheres empreendedoras e as feiras livres no litoral do paraná. Revista Faz Ciência, v. 18, n. 27, p. 118-39, 2016.

ANGULO, P. Pérdida de variedades locales de maíz. In: PALAU, M. Con la soja al cuello 2017 - informe sobre agronegocios en Paraguay. Asunción: BaselS, 2017. p. 78-81.

BOGADO MARTínEZ, N. C. Feria Jakaru Porã Haguã-Paraguay: los desafíos de la agricultura familiar. 2016. Trabajo de Conclusión de Curso (Desarrollo Rural y Seguridad Alimentaria) - Universidad Federal de la Integración Latinoamericana (Unila), Foz do Iguazú, 2016.

BORJA, R. M.; PADILLA, G.; ZAMBRANO, S.; OYARZUN, P. Creando y activando relaciones de confianza urbano-rurales en las redes alternativas de alimentos: experiencias en la sierra ecuatoriana. Leisa-Revista de Agroecologia, v. 33, n. 4, p. 15-18, 2017.

BURG, I. C. As mulheres agricultoras na produção agroecológica e na comercialização em feiras do sudoeste Paranaense. 2005. Disertación (Maestría en Agroecosistemas) - Universidade Federal de Santa Catarina, Florianópolis, SC, 2005.

CHENG, G.; LACROIX, P. Ferias y mercados de productores: hacia nuevas relaciones campo-ciudad. Lima: Cepes; AVSF, 2014.

COMISIÓN ECONÓMICA PARA AMÉRICA LATINA Y EL CARIBE (CEPAL). Encadenamientos productivos y circuitos cortos - innovaciones en esquemas de producción y comercialización para la agricultura familiar: análisis de la experiencia internacional y latinoamericana. Santiago: Cepal, 2016.

DAROLT, M. R.; LAMINE, C.; BRANDEMBURG, A. La diversidad de los circuitos cortos de alimentos ecológicos: enseñamientos del caso brasilero y francés. Agriculturas, v. 10, n. 2, p. 8-13, 2013.

DIRECCIÓN GENERAL DE ESTADÍSTICA, ENCUESTAS Y CENSOS (DGEEC). Atlas Demográfico del Paraguay, 2012. Asunción: DGEEC, 2016.

GAZOLLA, M.; SCHNEIDER, S. Cadeias curtas e redes agroalimentares alternativas. In: GAZOLLA, M.; SCHNEIDER, S. (Org.). Cadeias curtas e redes agroalimentares alternativas: negócios e mercados da agricultura familiar. Porto Alegre: Editora da UFRGS, 2017, p. 9-24.

GONZÁLES, H. Modalidad insostenible de consumo y expansión de la soja. In: PALAU, M. Con la soja al cuello 2017 - informe sobre agronegocios en Paraguay. Asunción: BaselS, 2017. p. 96-99. 
GOVERDE-LIPS, G.; BRUIL, J.; RENTING, H. Productores y consumidores construyendo nuevas prácticas alimentarias, Agriculturas, v. 12, n. 2, p. 39-43, 2015.

INSTITUTO NACIONAL DE DESARROLLO RURAL Y DE LA TIERRA. Feria "De la Colonia a tu Mesa" del Indert. Asunción: Indert, 2016.

MINISTERIO DE AGRICULTURA Y GANADERIA. Centro de Comercialización para Productores Asociados. Asunción: MAG, 2018.

MINISTERIO DE AGRICULTURA Y GANADERIA. Censo Agropecuario Nacional 2008. Asunción: MAG, 2009.

REAF- Reunión Especializada sobre Agricultura Familiar. Acta de la VII REAF: Anexo XII. Asunción, 2007.

RED RURAL. Agroecología en Paraguay. Experiencia de la Central de Productores Hortigranjeros Feriantes de Alto Paraná. Leisa - Revista de Agroecologia, edición especial, p. 56-64, 2016.

RIQUELME, Q. Agricultura Familiar Campesina en el Paraguay. Notas preliminares para su caracterización y propuestas de desarrollo rural. Centro de Análisis y Difusión de la Economía Paraguaya. Asunción: Cadep, 2016.

ROSSI, A.; BRUNORI, G.; GUIDI, F. I mercati contadini: un'esperienza di innovazione di fronte ai dilemmi della crescita. Rivista di diritto alimentare, v. 2, n. 3, p. 21-26, 2008.

TESSADA, M. San Francisco de Yuty: Origen y Desarrollo. Asunción, 2002.

TORRES FIGUEREDO, O. A. Agricultura familiar no leste do Departamento de São Pedro, Paraguai: origem, evolução, situação atual e perspectivas. 2008. Tesis de Doctorado. (Posgrado en Desarrollo Rural) Universidade Federal do Rio Grande do Sul, Porto Alegre, RS, 2008.

WILKINSON, J. Mercados, redes e valores: o novo mundo da agricultura familiar. Porto Alegre: Editora da UFRGS, 2008.

ZARZA, L. Paraguay. Situación actual de la Agricultura Familiar. Políticas Públicas y Marcos Institucionales. In: ADIB, A.; ALMADA, F. Políticas públicas y marcos institucionales para la agricultura familiar en América Latina. Chile: IICA, 2017, p. 396-439.

ZEEUW, H. Fortalecendo organizações de produtores e sua capacidade de comercialização: o programa "Da semente até a mesa" da RUAF. Revista de Agricultura Urbana, n. 24, p. 18-28, 2010.

\section{Sobre los autores:}

Francisca Danaides Carreras Rios: Maestría en Políticas Públicas y Desarrollo en la Universidad Federal de la Integración Latinoamericana (Unila). Licenciada en Desarrollo Rural y Seguridad Alimentaria en Unila. E-mail: dana94carreras@gmail.com, Orcid: http://orcid.org/0000-0002-0584-9332

Valdemar João Wesz Júnior: Doctor en Ciencias Sociales - Desarrollo, Agricultura y Sociedad en la Universidade Federal Rural do Rio de Janeiro (CPDA/UFRRJ). Profesor adjunto de la Universidad Federal de la Integración Latinoamericana (Unila). E-mail: jwesz@yahoo.com.br, Orcid: http://orcid.org/0000-0002-8154-7088 